\title{
Special Issue Editorial: Managing the supply chain management-marketing interface
}

\author{
Lucio Lamberti, Margherita Pero
}

Department of Management, Economics and Industrial Engineering, Politecnico di Milano, Milan, Italy

The ability to manage the interface between supply chain management and marketing processes (SCM-M interface) has profound implications for both the processes. From a marketing perspective, being able to collaborate with the supply chain increases the ability of gathering shared distribution-side and supply-side intelligence (e.g. Vargo et al. 2010; Esper et al. 2010; Gummesson 2008), thus increasing the ability to adopt market- and customer-oriented practices (e.g., Day 1995). From a supply chain management perspective, increasing collaboration with marketing process is vital to allow matching demand and supply, thus satisfying customers while increasing efficiency (Campo et al. 2000; Emmelheinz et al. 1991; Fitzsimons 2000; Gruen and Corsten 2007).

In todays' competitive scenario, where customers are increasingly demanding for an active role in innovation, customized approaches are dominant, thus making demand increasingly volatile, being able to manage SCM-M interface becomes more and more important. The companies that are failing to adopt a comprehensive set of tools for managing the SCM-M interface, despite they might be able to create differential advantages in one but not both of the domains, are not able to exploit the benefits of the integration (Esper et al., 2010).

It is hence clear that the SCM-M interface is becoming a critical success factor for organizations in many industries, and that business processes managing such interface require a deeper analysis and understanding, together with models and methods to foster future research.

Some years ago, we wrote a paper for BPMJ stressing how literature was falling short in proving managers with theoretical approaches, tools and best practices for such an integration (Pero and Lamberti, 2013). Over the last few years, the emphasis on the mutual impacts of marketing and SCM innovation have been increasingly an interestingly discussed by academicians with respect some paramount changes in the scenario, including the internet of things (Kamble et al., 2019), industry 4.0 (Ganji et al., 2018), omnichannel retailing (Adivar et al., 2019) and additive manufacturing (e.g., Durach et al., 2017), to name a few. Therefore, this special issue aims to move forward in the analysis and understanding of the marketingSCM relationship, interface and dynamics, by presenting a consistent collection of papers that provide significant new insights.

Out of the whole number of submissions received, after the review process, we accepted eight papers for publication in the special issue. The papers can be grouped into two main sets, depending on the topics examined. Specifically, two papers provide insights into the main trends and socio-economical changes that affect SCM-M interface and call for a profound reflection on how companies and supply chains should tackle such changes, while the remaining six papers provides insights on the techniques, approaches, tools and frameworks companies and supply chains can put in place to manage the SCM-M interface.

In the first group of papers, Noci (2019) discuss the relevance of the dramatic changes occurring in competition and market relationships on the integration between marketing and supply chain management processes. Leveraging on the literature, the author discusses an evolutionary pattern for SCM-M interface, considering the evolution of the market to always-on, service-dominant logic. In particular, he highlights the need in this context to be market-driving, and that the marketing strategy must be associated to a reconfiguration of the supply chain for providing value for customer. This results in profound organizational implications for marketing and supply chain management processes, and their interface, that go far beyond the simple implementation of technology. Alon et al. (2019) focuses on a specific initiative that is changing 
the global economic landscape: China's New Silk Road. The authors discuss the implications for European Small and Medium Enterprises (SMEs) and Chinese importers of the initiative. The investments in logistics infrastructures results in lower barriers to goods movement, therefore the need for both European SMEs and Chinese importers to re-organize their business in the light of this change. The paper discusses the need for European SMEs and Chinese importers to collaborate and integrate supply chain and marketing processes to reap the benefits of such initiative. In the end, the authors claim that, despite the economic relevance of the initiative, researchers and practitioners still need to reflect upon the implications for the supply chain actors in terms of business processes innovation.

In the second group of papers, the tools, frameworks and managerial approaches for putting in practice SCM-M interface are examined with different focuses and at different levels.

With a focus on a single company, at a more strategic level, Brun and Karaosman (2019) investigate the link between supply chain configuration choices and customers' features. In particular, they investigate how to include customers' expectations in supply chain configuration decisions. Through a set of case studies in the yacht industry, the authors highlight, for instance, that companies serving emotion-oriented customers, i.e. customers characterized by providing high relevance to brand reputation, and other brands' involvement in the final product and emotional appeal, design their supply chains to convey a direct emotional impact.

With a focus on a single company, at an operational level, Ardito et al. (2019) discusses the technological solutions that the new industrial revolution is providing to the companies for managing the SCM-M interface. In particular, this paper provides interesting information about the set of digital technologies that may enable the SCM-M integration, by showing how these solutions can support information acquisition, storage and elaboration. The discussion is supported by illustrative examples.

With a focus on the activities performed collaboratively across the supply chain, considering customer involvement, Nguyen and Harrison (2019) shows the implications for process innovation and performance of the acquisition of customer knowledge and knowhow. In particular, they performed a large-scale survey to test the relationships. Interestingly, they observed that process innovation plays a mediating role in absorbing and transforming customer knowledge into performance improvement. Thus, suggesting managers to use customer knowledge into process innovation. Given the importance for performance of customer involvement, Bettiga and Ciccullo (2019) investigate how suppliers and customers are involved in co-creation initiatives within product development processes. Based on the empirical evidences of crossindustry case studies, they propose a classification of the co-creation approaches (supplier-driven, customer-driven and firm-driven) and suggest contextual variables guiding the choice of which approach to implement.

With a focus on the industrial relationships between supply chain actors, Jie and Gengatharen (2019) investigate the benefits of supply chain integration in the food retail sector. They show that information sharing and the application of lean practices can improve supply chain efficiency. Interestingly, they analyze the Australian food retail supply chain and investigates specifically SMEs. Patrucco et al. (2019) study the context variables affecting the willingness to collaborate between buyer and supplier, through an international survey on manufacturing companies. The main result is that customer relationship attractiveness has a positive impact on both the innovation and cost performance ensured by suppliers. Additionally, other the antecedents of customer attractiveness have been identified: procurement knowledge and procurement status, and proficiency of supplier collaboration and visibility.

The topics addressed cover the main challenges companies are facing nowadays and the most important issues connected with SCM-M interface. Therefore, we believe this special issue can be of interest for both the scientific community and practitioners. However, despite the wide range of topics covered and the relevance of the results obtained, some questions are still open and further research is needed in this area. 
The changes in the marketplace that call for a deep innovation in marketing strategies and approaches must be accompanied by a change in the supply chain management practices and tools. The SCM-M interface plays a fundamental role in allowing the company to innovate the two processes and make the whole company moves at the same pace. We believe still there is a need of research in this area: the alignment of customers' features (Brun and Karaosman, 2019) to supply chain configuration is the first step, but an analysis of the further structural changes to supply chain management practices is foreseen. Technology is a powerful tool in supporting SCM-M integration (Ardito et al., 2019), however the full power of technology is expressed only when accompanied by a change in the business processes and the organization. We believe that there is still the need for understanding how SCM-M interface can be (re)design to foster the new technologies potential.

Considering the relationships at supply chain level, the changes in the marketplace call for a stronger integration of customer into product or service innovation processes. Bettiga and Ciccullo (2019) made an interesting attempt to investigate supplier and customer involvement in the same project, however how to reap completely the benefits of such collaboration and how to structure the interaction flows between the actors is still under-investigated.

Finally, Alon et al. (2019) suggest that, in the near future, initiatives such as the one of the China Silk Road will require companies more and more to manage SCM-M interface among countries and cultures. Therefore, we hope researchers will tackle the cultural issues and management style differences in SCM-M interface, to provide managers with theoretical support when managing multi-cultural teams.

In conclusion, we would like to thank Professor Majed Al-Mashari, editor in chief of the Business Process Management Journal for allowing us to serve as guest editors, all the authors that have submitted their work for this special issue, and the reviewers that have contributed to ensure the academic level of the works accepted. A special acknowledgement goes to Maria Caridi, who began this adventure with us and, along the process, decided to open a new chapter of her personal and professional life; we wish her all the best and thank for the contribution all along the first phases of this venture.

\section{References}

Adivar, B., Hüseyinoğlu, I.Ö.Y., Christopher, M. (2019). A quantitative performance management framework for assessing omnichannel retail supply chains (2019) Journal of Retailing and Consumer Services, 48, pp. 257-269.

Campo, K., Gijbrechts, E., and van Nisol, P. (2000). "Towards understanding consumer response to stockouts", Journal of Retailing, Vol. 76, No. 2, pp. 219-242.

Durach, C.F., Kurpjuweit, S., Wagner, S.M. (2017) The impact of additive manufacturing on supply chains. International Journal of Physical Distribution and Logistics Management, 47 (10), pp. 954-971.

Emmelheinz, M. A., Stock, J. R., and Emmelheinz, L. W. (1991). "Consumer response to retail stock-outs". Journal of Retailing, Vol. 67, No. 2, pp. 138-147.

Esper, T.L., Ellinger, A.E., Stank, T.P., and Flint, D.J., Moon, M (2010). “Demand and supply integration: A conceptual framework of value creation through knowledge management", Journal of the Academy of Marketing Science, Vol. 38, No. 1, pp. 5-18.

Fitzsimons, G. J. (2000). "Consumer response to stockouts". Journal of Consumer Research, Vol. 27, No. 2, pp. 249-266. 
Ganji, E.N., Coutroubis, A., Shah, S. (2018) DCM 4.0: Integration of Industry 4.0 and Demand Chain in Global Manufacturing. 2018 IEEE International Conference on Engineering, Technology and Innovation, ICE/ITMC 2018 - Proceedings, art. no. 8436383

Gruen, T. W., and Corsten, D. (2007). A comprehensive guide to retail out-of- stock reduction in the fastmoving consumer goods industry. Grocery Manufacturers Association, Food Marketing Institute, and National Association of Chain Drug Stores, Washington, DC.

Gummesson, E. (2008). "Extending the service-dominant logic: From customer centricity to balanced centricity" Journal of the Academy of Marketing Science, Vol. 36, No. 1, pp. 15-17.

Kamble, S.S., Gunasekaran, A., Parekh, H., Joshi, S.(2019). Modeling the internet of things adoption barriers in food retail supply chains. Journal of Retailing and Consumer Services, 48, pp. 154-168.

Pero, M., \& Lamberti, L. (2013). The supply chain management-marketing interface in product development: an exploratory study. Business Process Management Journal, 19(2), 217-244. 